\title{
Influence of Bleaching Materials on Mechanical and Morphological Properties for Paper Conservation
}

\author{
A. M. Rushdy ${ }^{1}$, W. N. Wahba ${ }^{2}$, A. M. Youssef ${ }^{3 *}$ and S. Kamel ${ }^{4}$ \\ ${ }^{1}$ Conservation Department, Museum of Islamic Art, Cairo, Egypt ${ }^{2}$ Faculty of \\ Archaeology, Cairo University, Egypt ${ }^{3}$ Packaging and Packing Materials Department, \\ National Research Centre, El Behooth St., Dokki - Giza-Egypt and ${ }^{4}$ Cellulose and \\ Paper Department, National Research Centre, El Behooth St., Dokki - Giza-Egypt.
}

\begin{abstract}
O LD historical papers always are suffering from yellowing and darkness specifically after natural aging, so this study aim to evaluated some traditional bleaching materials that used in treatments of documents and books like hydrogen peroxide and sodium borohydride. Physical and chemical changes in paper sheets (cotton linter paper and book) before and after aging were studied such as color change, $\mathrm{pH}$ measurements, tensile strength, burst strength, FT-IR spectrum and scanning electron microscopy (SEM). The result pointed out that $\mathrm{H}_{2} \mathrm{O}_{2} \&$ $\mathrm{NaBH}_{4}$ lead to no significant improvement in mechanical properties of the historical paper. The effect of $\mathrm{H}_{2} \mathrm{O}_{2}$ and $\mathrm{NaBH}_{4}$ concentration, bleaching time and $\mathrm{pH}$ on paper sheet bleaching process were examined. Whiteness and yellowness results of the historical paper were evaluated for both bleaching methods. From this work it is clear that, it is not desirable to utilize bleaching agents for the treatment and conservation of ancient archaeological papers, but only in the essential cases they may be used in slight concentrations to treat yellowing, staining or stains.
\end{abstract}

Keywords: Historical papers, Bleaching, Hydrogen peroxide, Sodium borohydride, Thermal Aging.

\section{Introduction}

In general paper consists of bonded cellulose fibers that are linear polymers of glucose ( $(-\mathrm{D}-$ glucopyranose) monomers liked by $\beta-1$, 4-glycosidic bonds, hemicellulose, lignin and certain amount of additives e.g. fillers, pigments, metal ions, sizing and bleaching substances [1]. There are diverse mechanisms that cause the deterioration of paper. Storage under normal conditions, degradation processes are very slow but eventually generate yellowing and loss of the paper mechanical strength [2]. The paper degrades naturally throughout three main reactions: acid-catalyzed hydrolysis of cellulose molecules, oxidative degradation induced from atmospheric oxygen and light, and thermal degradation that leads to chemical bond breakage as the temperature is increased. Artificial paper aging tests have demonstrated that these reactions become more intense when temperature is incremented [3]. Yellowing caused by aging, foxing that can appear due to iron oxidation or because of the presence of microorganisms $[4,5]$.
Bleaching process is used to clean the historical paper and it is classified under wet treatments. Since the bleaching agent is usually applied as a solution, the main purpose of bleaching is cosmetic, that is the removal of the overall discoloration or of disfiguring stains. But bleaching process destroys chromophore groups by either oxidation or reduction, depending on the kind of the bleaching reagent [6]. Bleaching can convert a conjugated double bond to carboncarbon single bond which removes discoloration from paper [7]. Many paper conservators use hydrogen peroxide [8] in widely to bleach discolored or stained paper.It is generally considered more environmentally friendly than other bleaching agents and it can be minimized by using low concentration of alkaline solutions [9]. Also sodium borohydride can be used [1013] compared between the effect of thermal aging on physical and chemical properties of historical paper. Paper aging and conservation are substances of anxiety to those accountable for

\footnotetext{
*Corresponding author e-mail: amyoussef27@yahoo.com 
archives and library collections [14].

Consequently, paper is a multi-component fabric, and owing to its difficult and diverse nature, investigate result in paper chemistry could be hard to understand. Therefore, the source of the cellulosic matter, and pulping as well as papermaking methods, additives, and storage situation play a vital role [15-18]. Also, the chemical changes happening in the paper accordingly engage multi-parameter developments.

Accordingly, the key purpose of this study has been assesed the effect of bleaching materials such as hydrogen peroxide and sodium borohydride on the mechanical, thermal and morphological properties of paper documents and books before and after treatments via thermal aging.

\section{Materials and Methods}

\section{Materials}

Cotton linter, delivered by Abo Zaable Chemicals Company (Abo Zaable, Egypt) and PARIS Book paper (dating back to 1887 A.D.) Book paper has natural aging about 220 years addition to thermal aging 25 years was used in this work. Hydrogen Peroxide and Sodium Borohydride $\left(\mathrm{H}_{2} \mathrm{O}_{2} \& \mathrm{NaBH}_{4}\right)$ of analytical grade were used.

\section{Methods}

Paper manufacture from cotton linter pulp

It has been done in the Egyptian National Library and Archives (Dar al Kutub) Corniche El Nile, Sabttiya according to the following method; pulp was beaten to $40{ }^{\circ} \mathrm{SR}$ in a Jokro mill beater according to the Swedish Standard Method (SCA). Sheets of basis weight $80 \mathrm{~g} / \mathrm{m}^{2}$ were formed using leaf cast instrument. The paper sheets were prepared according to the S.C.A standard, using the model S.C.A sheet former (AB Worentzen and Wettre). In the apparatus a sheet of $165 \mathrm{~mm}$. diameter and $214 \mathrm{~cm}^{2}$ surface area was formed. The weight of oven dry pulp used for every sheet was about $1.43 \mathrm{~g}$. paper sheets were dipped in $1 \%$ solution of carboxy methyl cellulose. After dipping, the paper sheets were pressed between two filter paper sheets to remove the excess polymer. After sheet formation, the sheet was pressed for 4 min using a hydraulic press. Drying of the test sheets was made with the help of a rotating cylinder or drum dryer at $60{ }^{\circ} \mathrm{C}$ +5 for $2 \mathrm{~h}$ ) to produce sheet dimension of $62 \times 42$ $\mathrm{cm}$, then dried using dryer under pressure. Yellow spots have been made by rummage of iron metal powder on the surface of the paper sheets.

\section{Bleaching}

Paper treatment by bleaching in immersion of hydrogen peroxide or sodium borohydride ( 0.5 and $1 \%$ ) of each solution

Thermal aging of paper using $\left(\mathrm{H}_{2} \mathrm{O}_{2} \&\right.$ $\mathrm{NaBH}_{4}$ ): According to TAPPI standard T453 ts63 untreated and treated sample were hung in a drying oven (Heraeus type 5042) Kotter manual hansen w- Germany set at $100^{ \pm} 5^{\circ} \mathrm{C}$ for 3 days $(\approx 72 \mathrm{~h}$ ), this period was selected to be equivalent to 25 years of natural aging $[19,20]$. The book paper has natural aging about 220 years addition to thermal aging 25 years.

\section{Characterization}

\section{pH measurements}

The $\mathrm{pH}$ of papers is considered as the most important factor determining its stability towards natural and accelerated ageing. Cold extraction measurements conformed to TAPPI standard T509 om-11 was used [21, 22].

\section{Tensile strength}

The tensile properties of the paper are tested with a testing machine, as specified in the TAPPI standard T 494 om-01; The untreated and treated paper samples were kept in the conditioned room for $24 \mathrm{~h}$, and the testing of tensile strength in a standard atmosphere (at temperature of $23 \pm$ $1{ }^{\circ} \mathrm{C}$ and relative humidity(RH) $50 \pm 0.2 \%$ [23]. Tensile testing was carried out on $15 \mathrm{~mm}$ wide strips between jaws set $100 \mathrm{~mm}$ apart, using a universal testing machine, model 4201 from Instorn Corporation equipped with a tension cell of $500 \mathrm{~N}$ at a stretching speed of $5 \mathrm{~mm} / \mathrm{min}$.

Breaking Length $(\mathrm{m})=$ Tensile strength $(\mathrm{mm})$ X 6, 67 X 10,000 / Grammage (g)

Grammage, i.e. weight of $1 \mathrm{~m}^{2}$, from it the retained amount $\left(\mathrm{g} / \mathrm{m}^{2}\right)$ of materials or its derivatives on paper sheets were calculated [24].

\section{Burst strength}

Burst strength was measured according to TAPPI standard T403 om-02(TAPPI 1997). This test is designed to measure the maximum bursting strength of the paper between $50 \mathrm{kPa}$ and 1200 $\mathrm{kPa}$ with maximum thickness of $0.6 \mathrm{~mm}$. The standard size of samples is $10 \times 10 \mathrm{~cm}$, they 
are clamped between two concentric annuli on the rubber diaphragm. The pressure causes the sample to expand into the upper annular clamp until it bursts [25].

\section{Color change}

Color changes caused by the effect of accelerated aging cycles were measured using CIE *Lab system commonly used to compare the colors of two samples. The L-scale measures lightness, and varies from 0(black) to 100 (perfect white). The a-scale measures red-green; (+a) means more red, (-a) measures green; the b-scale measures yellow-blue; $(+b)$ meaning more yellow, (-b) deep blue [26]. The total color difference $(\Delta \mathrm{E})$ is calculated according to the following equation:

$$
\Delta \mathrm{E}=\sqrt{(\Delta \mathrm{L})^{2}+(\Delta \mathrm{a})^{2}+(\Delta \mathrm{b})^{2}}
$$

The measurement was made using Ultra Scan
PRO Hunter Lab D65, 10 A.

Infrared spectroscopy (FTIR) analysis

Infrared spectroscopy using Fourier transform infrared (FTIR) investigation was achieved with a JASCO FTIR-6100E spectrometer, Japan.

\section{Scanning Electron Microscopy (SEM)}

Samples for SEM were taken using FEI Netherlands Model Quanta 200 environmental scanning electron microscope with EDX unit. Elemental micro-probe was used for analyzing the elemental constitution of solid samples, to observe the surface morphology [27].

\section{$\underline{\text { Results and Discussion }}$}

\section{pH measurements}

Bleaching action increases with increasing $\mathrm{pH}$ as does rate of degradation [28]. A correct deacidification process is keeping the $\mathrm{pH}$ around 8-9. Table 1 demonstrated that the $\mathrm{pH}$ values on

TABLE 1. pH values of cotton linter and book paper.

\begin{tabular}{|lcccc|}
\hline & \multicolumn{2}{c}{ Cotton linter paper } & \multicolumn{2}{c|}{ Book paper } \\
\hline Bleaching materials & Before aging & After aging & Before aging & After aging \\
\hline Unbleached & 6.61 & 6.57 & 6.75 & 6.51 \\
& & $0.5 \%$ Bleaching Agent & & 7.45 \\
$\mathrm{H}_{2} \mathrm{O}_{2}$ & 8.34 & 7.82 & 7.50 & 9.45 \\
$\mathrm{NaBH}_{4}$ & 9.49 & 9.45 & 9.65 & 7.05 \\
& & $1 \%$ Bleaching Agent & & 9.35 \\
$\mathrm{H}_{2} \mathrm{O}_{2}$ & 8.23 & 7.96 & 7.35 & 9.46 \\
$\mathrm{NaBH}_{4}$ & 9.49 & 9.37 & & \\
\hline
\end{tabular}

the surface of untreated and treated samples of cotton linter and book paper from the Table, all samples showed increasing in $\mathrm{pH}$ after bleaching either by $\mathrm{H}_{2} \mathrm{O}_{2}$ or $\mathrm{NaBH}_{4}$. Aging reduced the $\mathrm{pH}$ paper that bleached by $\mathrm{H}_{2} \mathrm{O}_{2}$ although the $\mathrm{pH}$ remains constant by bleaching using $\mathrm{NaBH}_{4}$ with different concentrations. In general, the $\mathrm{pH}$ of the bleached paper using $\mathrm{NaBH}_{4}$ solutions is higher than that bleached by $\left(\mathrm{H}_{2} \mathrm{O}_{2}\right)$ solutions.

\section{Breaking length}

The bleaching of pulp improved the apparent density, From Fig. 1 the breaking length of bleaching materials $\left(\mathrm{H}_{2} \mathrm{O}_{2}\right.$ and $\left.\mathrm{NaBH}_{4}\right)$ after bleaching in case of cotton linter paper, the breaking length decreased with increasing the concentration of bleaching materials and decreased compare with the blank, while the breaking length of bleaching materials $\left(\mathrm{H}_{2} \mathrm{O}_{2}\right.$ and $\left.\mathrm{NaBH}_{4}\right)$ before bleaching in case of cotton linter paper increased compare with blank and no significant change in the two bleaching materials used.

From Fig. 2 the breaking length of bleaching materials $\left(\mathrm{H}_{2} \mathrm{O}_{2}\right.$ and $\left.\mathrm{NaBH}_{4}\right)$ after bleaching materials in case of book paper increased with rising the dose amounts of $\left(\mathrm{H}_{2} \mathrm{O}_{2}\right.$ and $\left.\mathrm{NaBH}_{4}\right)$ and also decreased compare with the blank, while the breaking length of bleaching materials $\left(\mathrm{H}_{2} \mathrm{O}_{2}\right)$ before bleaching in case of book paper increased in case of using $\mathrm{NaBH}_{4}$ and decreased when using $\mathrm{H}_{2} \mathrm{O}_{2}$ contrast with blank. All in all, The Tensile 
strength, burst index and brightness of the paper decreased, due to the removal of lignin during the bleaching process probably increased the bonding strength [29].

\section{Burst strength}

Figure 3 displayed that the burst strength of bleached papers on cotton linter paper before and after aging, which decreased by increasing the bleaching agents and increased compare to the blank (cotton linter paper). The same phenomenon was observed in case of using book. Although the burst strength increase with rising the concentration of the bleaching materials
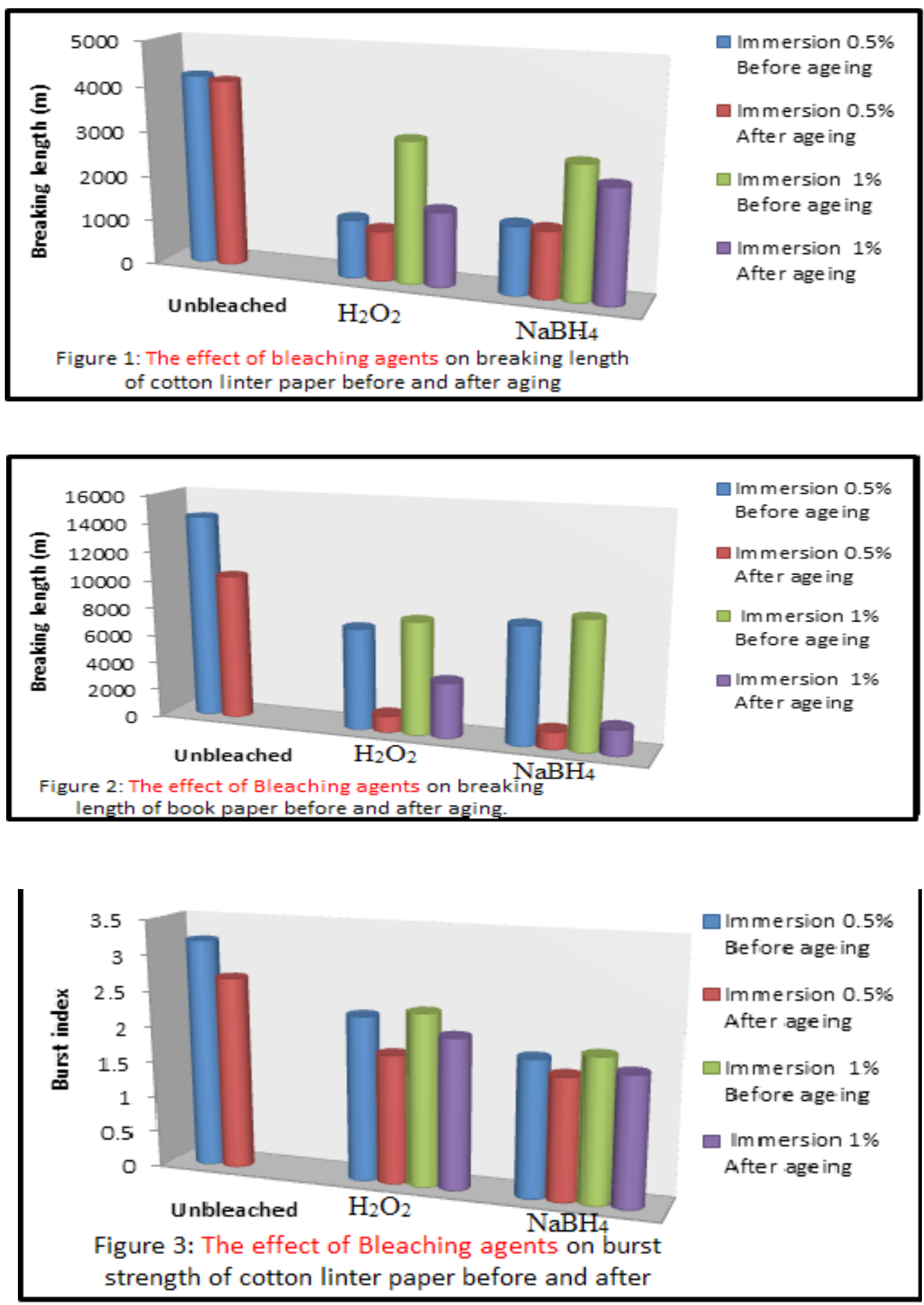

Egypt.J.Chem. 60 , No. 5 (2017) 


\section{Measurement of color change}

The effect of color changes on cotton linter paper and book paper with bleaching using $\left(\mathrm{H}_{2} \mathrm{O}_{2}\right.$ and $\mathrm{NaBH}_{4}$ ) before and after aging was shown in Table 2( $a$ and $b$ ). The change in color increased with rising the concentrations of the bleaching agents $\left(\mathrm{H}_{2} \mathrm{O}_{2}\right.$ and $\left.\mathrm{NaBH}_{4}\right)$ after and before aging, the change in color was more significant when using high concentration of bleaching agents (1\%) of both $\left(\mathrm{H}_{2} \mathrm{O}_{2}\right.$ and $\left.\mathrm{NaBH}_{4}\right)$ particularly when utilizing cotton linter paper after aging. Furthermore, the influence of aging was more significant when using $1 \% \mathrm{NaBH}_{4}$ as bleaching agent rather than the using of $1 \% \mathrm{H}_{2} \mathrm{O}_{2}$ in both cotton linter paper and book paper after aging.

\section{Infrared spectroscopy}

The FT-IR spectral results for all papers which untreated and treated with bleaching agents were quite similar. As shown in Fig. 4a,
$4 \mathrm{~b}, 4 \mathrm{c}$ and $4 \mathrm{~d}$, the FT-IR spectra revealed that all paper types had a peak around $3300 \mathrm{~cm}^{-1}$ hydroxyl groups $(-\mathrm{OH})$, and also had a peak around $2900 \mathrm{~cm}^{-1}$ hydrocarbon groups $(-\mathrm{CH})$, $1550: 1610 \mathrm{~cm}^{-1}$ H-O-H absorbed for water, 1300:1420 $\mathrm{cm}^{-1}$ carboxylate (carboxylic acid salt) [30].There is a considerable difference in the band at1028 $\mathrm{cm}^{-1}$, which corresponds to $\mathrm{C}-\mathrm{O}$ ether bonds, suggesting a dissociation of bonds as a result of supplementary photochemical degradation [31]. In the samples of book paper had a peak $1661 \mathrm{~cm}^{-1}$ which signified the attendance of carbonyl groups $(\mathrm{C}=\mathrm{O})$ which are a product of the degradation of cellulose [32], $1725 \mathrm{~cm}^{-1}$ an oxidation of paper, that be able to follow the degradation of cellulose aged under a variety of conditions [33]. The all spectra at different conditions almost matching as revealed in Figs. 4a, 4b, 4c and 4d.

TABLE 2a. effect of bleaching materials on color changes of cotton linter paper before and after aging

\begin{tabular}{|c|c|c|c|c|c|c|c|c|}
\hline & \multicolumn{4}{|c|}{ Before aging } & \multicolumn{4}{|c|}{ After aging } \\
\hline \multirow{2}{*}{ Unbleached } & $\mathrm{L}$ & A & $\mathrm{b}$ & $\Delta \mathrm{E}$ & $\mathrm{L}$ & $\mathrm{a}$ & $\mathrm{b}$ & $\Delta \mathrm{E}$ \\
\hline & 87.74 & 23 & 5.20 & 0.0 & 84.42 & 0.22 & 9.68 & 0.0 \\
\hline \multicolumn{9}{|c|}{ Immersion $0.5 \%$} \\
\hline $\mathrm{H}_{2} \mathrm{O}_{2}$ & 84.93 & 0.1 & 5.02 & 2.80 & 82.46 & 2.02 & 14.99 & 5.95 \\
\hline $\mathrm{NaBH}_{4}$ & 86.54 & 0.44 & 5.63 & 1.28 & 82.89 & 1.97 & 13.45 & 4.44 \\
\hline \multicolumn{9}{|c|}{ Immersion $1 \%$} \\
\hline $\mathrm{H}_{2} \mathrm{O}_{2}$ & 85.12 & 0.71 & 8.13 & 3.95 & 83.57 & 2.98 & 17.47 & 8.30 \\
\hline $\mathrm{NaBH}_{4}$ & 84.82 & 1.01 & 8.82 & 4.72 & 80.24 & 5.26 & 20.40 & 12.57 \\
\hline
\end{tabular}

TABLE 2b, effect of bleaching materials on color changes of book paper before and after aging.

\begin{tabular}{|lcccccccc|}
\hline & \multicolumn{3}{c}{ Before aging } & \multicolumn{5}{c|}{ After aging } \\
\hline & $\mathrm{L}$ & $\mathrm{A}$ & $\mathrm{b}$ & $\Delta \mathrm{E}$ & $\mathrm{L}$ & $\mathrm{a}$ & $\mathrm{b}$ & $\Delta \mathrm{E}$ \\
Unbleached & 89.28 & 0.67 & 9.30 & 0.0 & 84.36 & 2.19 & 15.00 & 0.0 \\
Immersion $0.5 \%$ & & & & & & & & \\
$\mathrm{H}_{2} \mathrm{O}_{2}$ & 90.42 & 0.55 & 7.70 & 1.97 & 89.61 & 0.94 & 10.20 & 7.22 \\
$\mathrm{NaBH}_{4}$ & 90.71 & 0.52 & 8.37 & 1.72 & 87.92 & 1.45 & 11.72 & 4.86 \\
& & & & Immersion $1 \%$ & & & & \\
$\mathrm{H}_{2} \mathrm{O}_{2}$ & 87.31 & 1.56 & 10.42 & 2.43 & 88.93 & 1.19 & 10.54 & 6.43 \\
$\mathrm{NaBH}_{4}$ & 88.66 & 1.56 & 13.23 & 4.08 & 88.99 & 0.83 & 10.09 & 7.14 \\
\hline
\end{tabular}



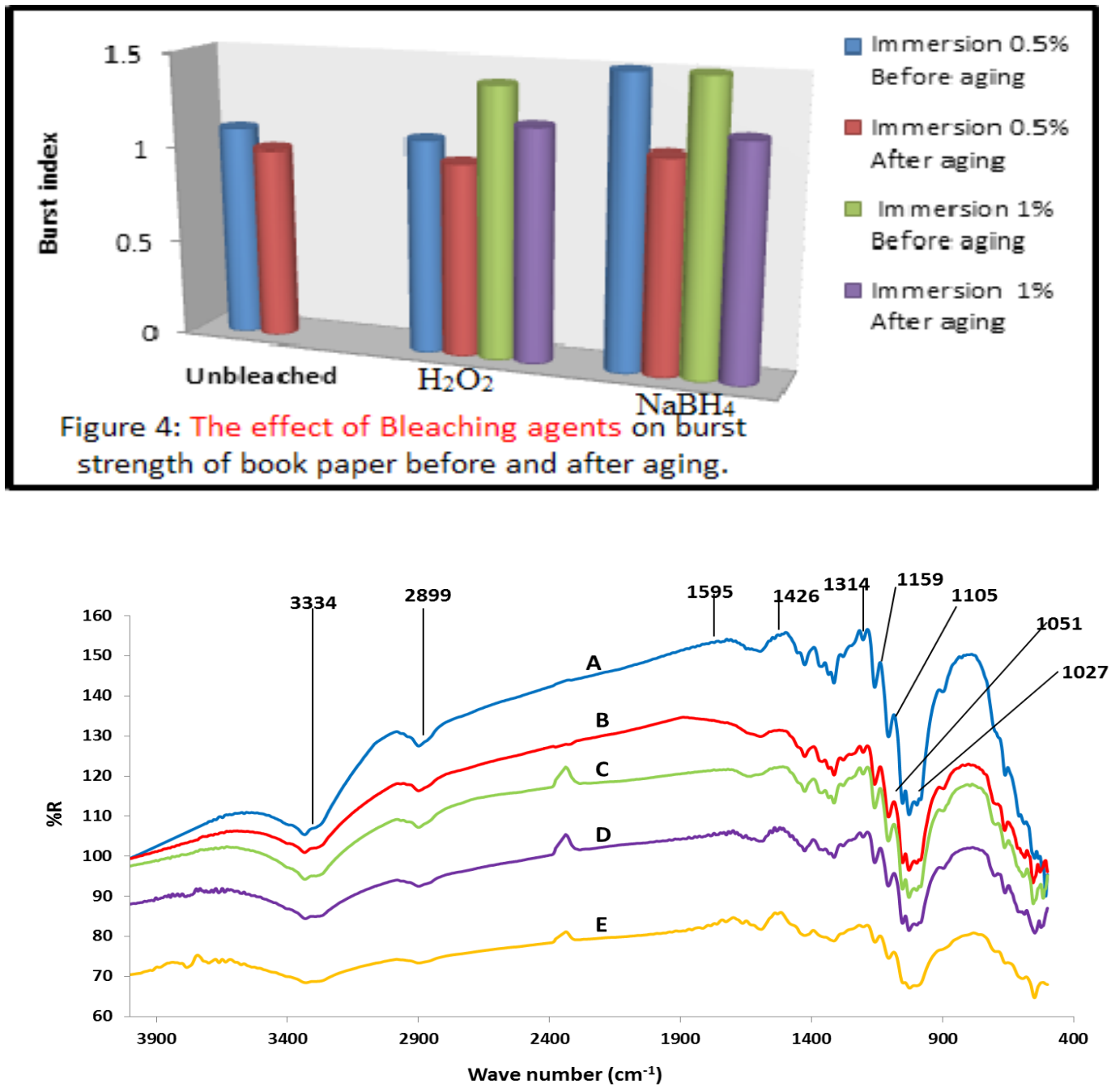

Fig. 4a. FT-IR spectroscopy of cotton linter paper before aging: (A) unbleached, (B) $0.5 \% \mathrm{H}_{2} \mathrm{O}_{2}$, (C) $1 \% \mathrm{H}_{2} \mathrm{O}_{2}$, (D) $0.5 \% \mathrm{NaBH}_{4}$, and (E) $1 \% \mathrm{NaBH}_{4}$.

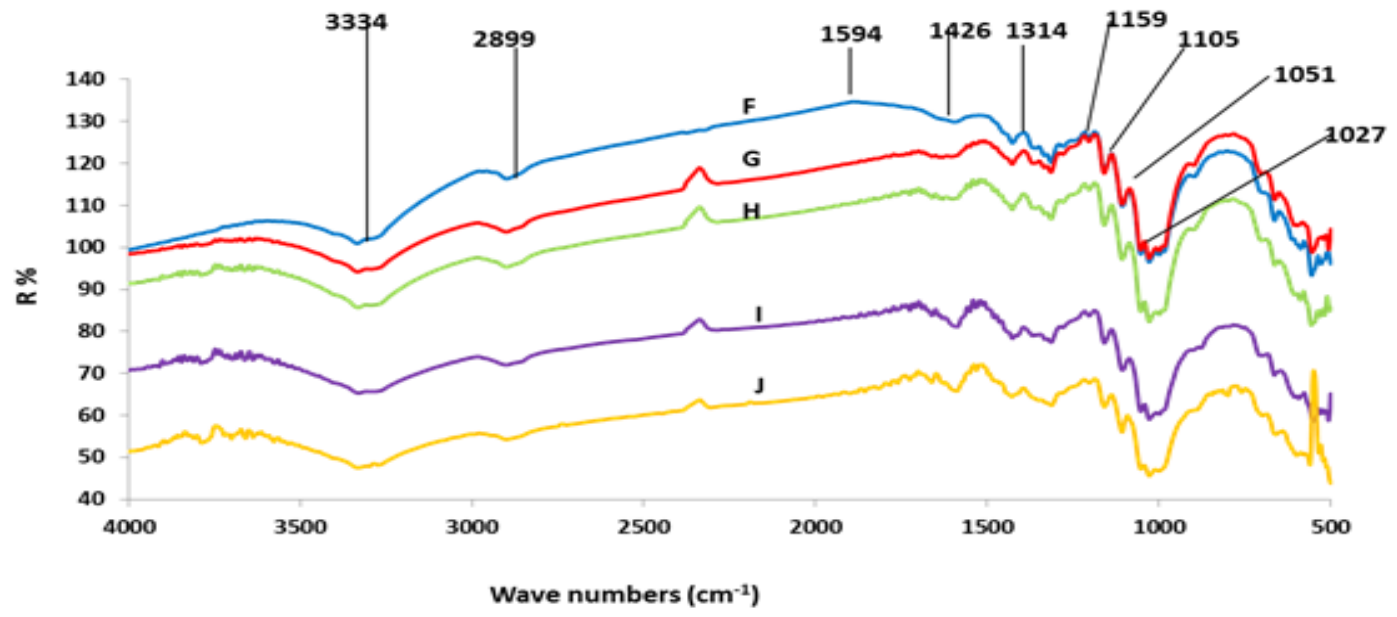

Fig. 4b. FT-IR spectroscopy of cotton linter paper after aging: (F) unbleached, (G) $0.5 \% \mathrm{H}_{2} \mathrm{O}_{2},(\mathrm{H}) 1 \% \mathrm{H}_{2} \mathrm{O}_{2}$, (I) $0.5 \% \mathrm{NaBH}_{4}$, and (J) $1 \% \mathrm{NaBH}_{4}$. 


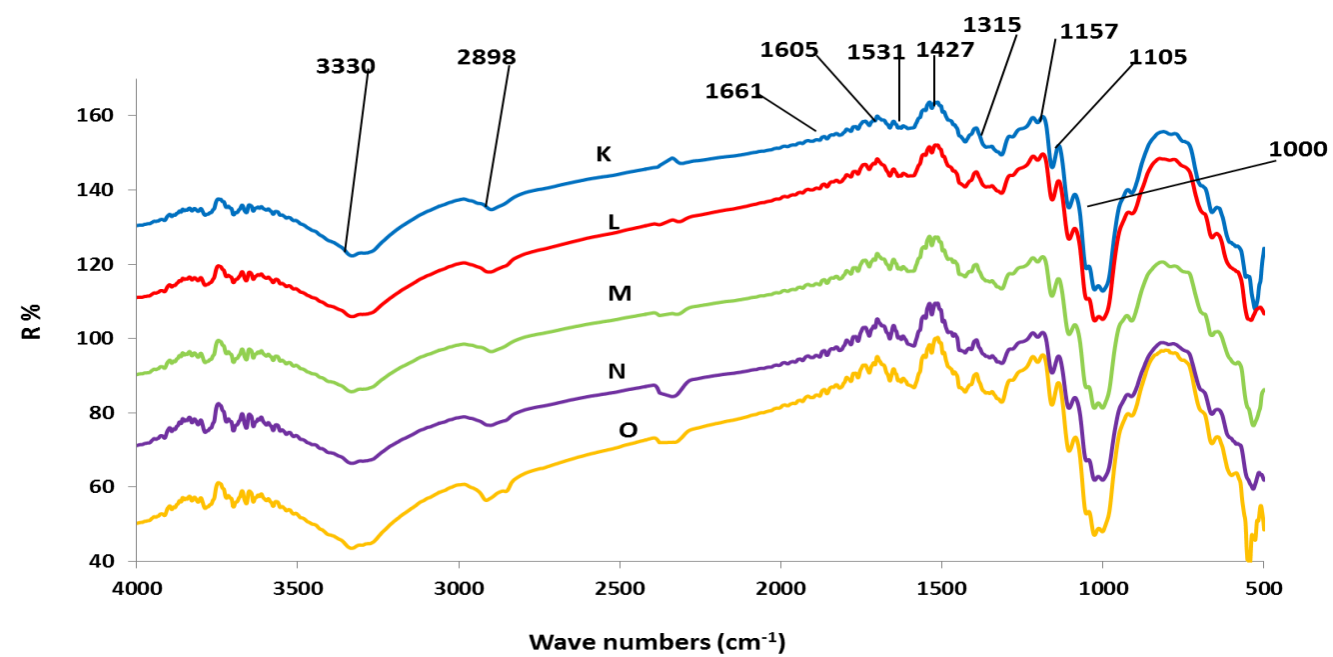

Fig. 4c. FT-IR spectroscopy of book paper before aging: (K) unbleached, (L) $0.5 \% \mathrm{H}_{2} \mathrm{O}_{2},(\mathrm{M}) 1 \% \mathrm{H}_{2} \mathrm{O}_{2}$, (N) $0.5 \%$ $\mathrm{NaBH}_{4}$, and (O) $1 \% \mathrm{NaBH}_{4}$.

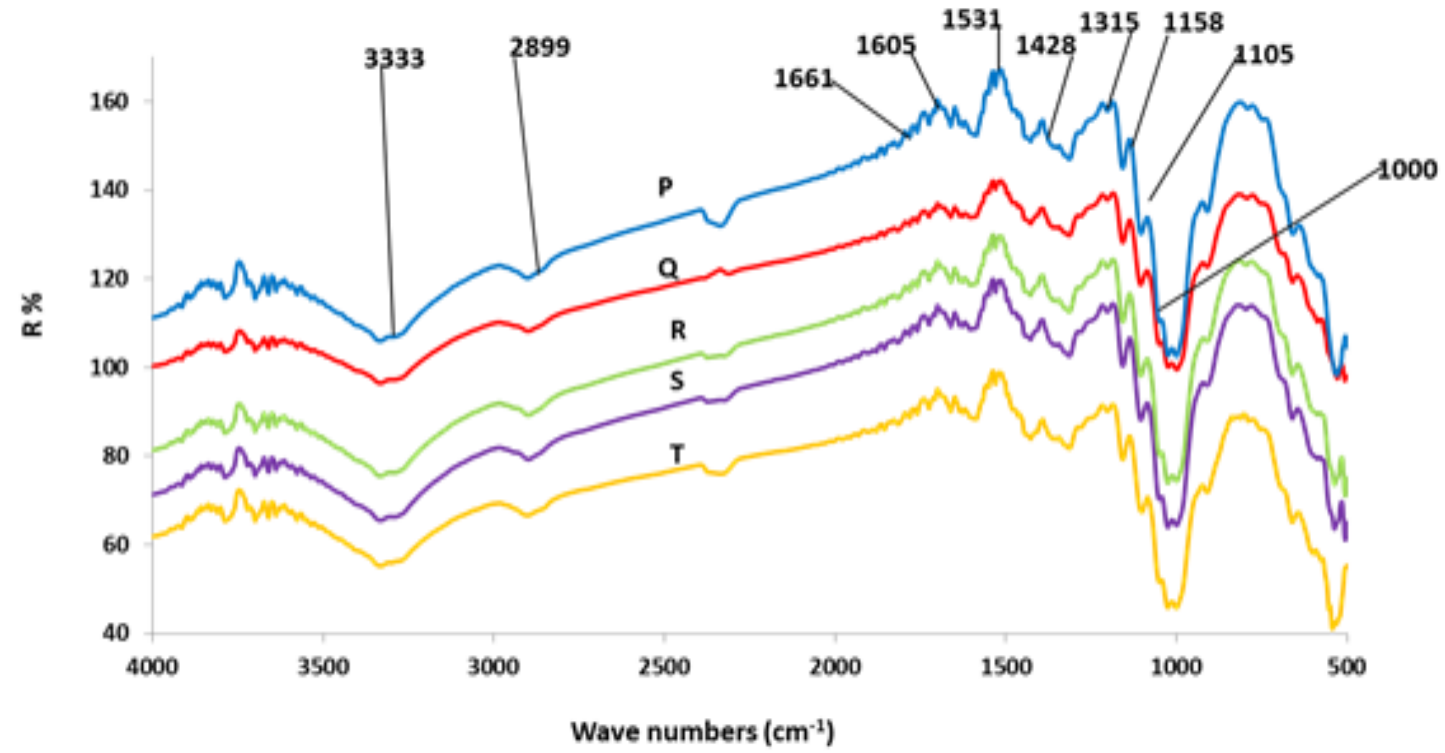

Fig. 4d. FT-IR spectroscopy of book paper after aging: (P) unbleached, (Q) $0.5 \% \mathrm{H}_{2} \mathrm{O}_{2},(\mathrm{R}) 1 \% \mathrm{H}_{2} \mathrm{O}_{2}$, (S) $0.5 \%$ $\mathrm{NaBH}_{4}$ and (T) $1 \% \mathrm{NaBH}_{4}$.

(H2O2 and $\mathrm{NaBH} 4)$ before aging.

There was no noticeable change in the cotton paper; while in the book paper the functional groups showed the oxidation and damage of cellulose.This may be due to the length of the aging period of the paper compared to the cotton paper. These results are confirmed when investigation paper fibers with a scanning electron microscope.
Morphological Investigation via Scanning Electron Microscopy (SEM)

The morphological properties of the cotton linter before and after aging were revealed in Fig. 5. It has been indicated that the blank of cotton linter before aging (Fig. 5a and k) is very good fibril structure and the fiber was clear and smooth while after using the two bleaching materials $\left(\mathrm{H}_{2} \mathrm{O}_{2}\right.$ and $\left.\mathrm{NaBH}_{4}\right)$ the fiber of paper start to degrade. Whereas, the 

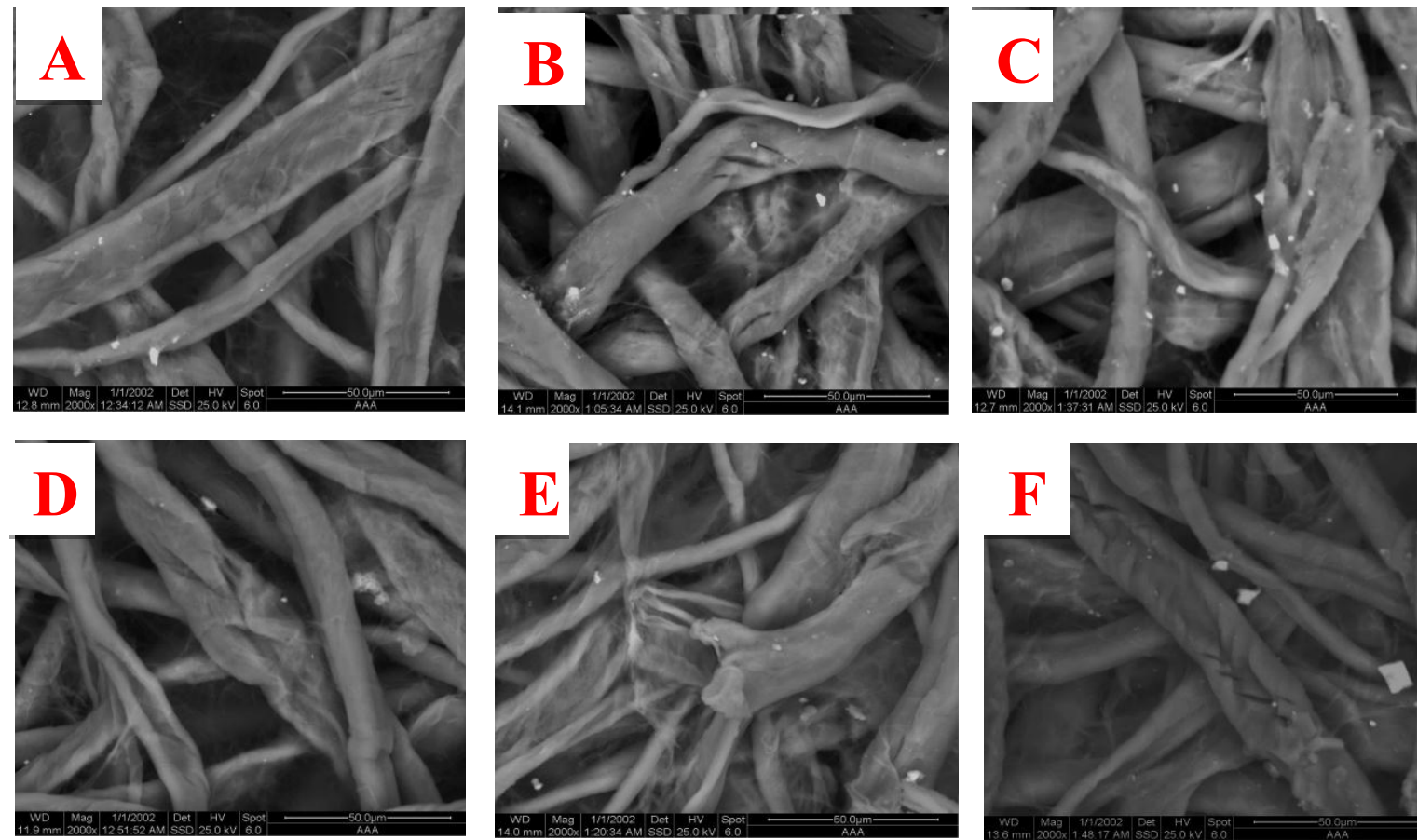

Fig. 5. SEM of non aged cotton linter paper ((A) unbleached, (B) bleached by $\mathrm{H}_{2} \mathrm{O}_{2},(C)$ bleached by $\left.\mathrm{NaBH}_{4}\right)$; aged cotton linter paper ((E) bleached by $\mathrm{H}_{2} \mathrm{O}_{2},(\mathrm{~F})$ bleached by $\left.\mathrm{NaBH}_{4}\right)$

high concentrations of $\left(\mathrm{H}_{2} \mathrm{O}_{2}\right.$ and $\left.\mathrm{NaBH}_{4}\right)$ is completely decomposed due to the effect of aging.
The morphology of the book paper before and after aging was revealed in Fig. 6. It has been indicated that the blank of book paper before aging as shown in Fig. 6 (a \& k) is very good
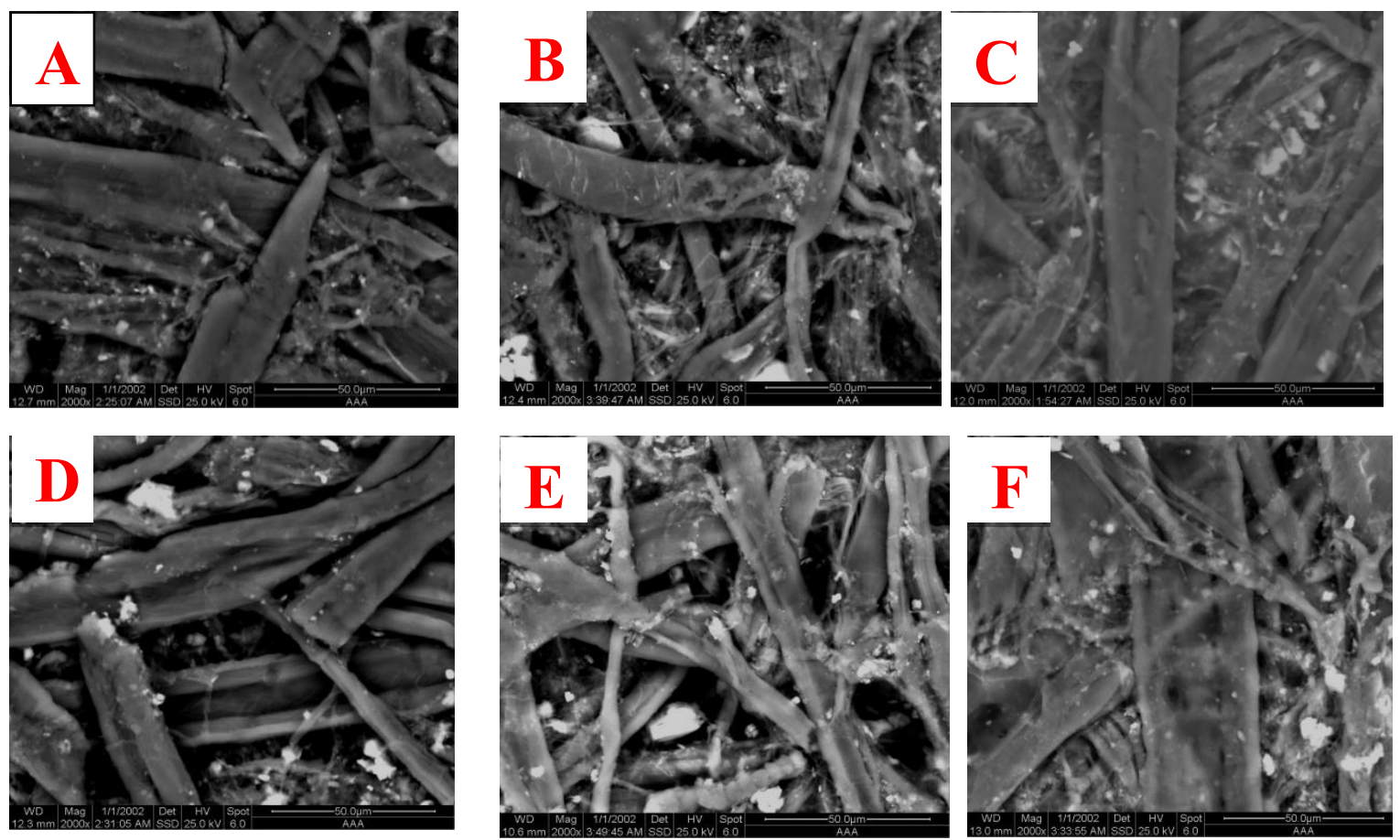

Fig. 6. SEM of non aged book paper ((A) unbleached, (B) bleached by $\mathrm{H}_{2} \mathrm{O}_{2},(\mathrm{C})$ bleached by $\left.\mathrm{NaBH}_{4}\right)$; aged book paper ((E) bleached by $\mathrm{H}_{2} \mathrm{O}_{2},(\mathrm{~F})$ bleached by $\left.\mathrm{NaBH}_{4}\right)$.

Egypt.J.Chem. 60 , No. 5 (2017) 
fibril structure and the fiber was clear and smooth while after using the two bleaching agents $\left(\mathrm{H}_{2} \mathrm{O}_{2}\right.$ andNaBH${ }_{4}$ ) the fiber of paper start to degrade. Whereas, the using of high concentrations of $\mathrm{H}_{2} \mathrm{O}_{2}$ and $\mathrm{NaBH}_{4}(1 \%)$ was completely decomposed attributable to the effect of aging.

\section{Conclusion}

There was an improvement in the mechanical properties of the paper, especially with a concentration of bleaching chemicals less $0.5 \%$. But in the chemical properties of pulp fibers, there was no noticeable change in the cotton paper, while in the book paper the functional groups showed the oxidation and damage of cellulosic fibers. As in the color changes of the paper did not notice any change by visual observation, but the results of measurements resulted in the existence of changes in the best and specific values of whiteness and yellowing.

From the current study it is clear that, it is not desirable to use bleaching agents for the treatment and conservation of ancient archaeological papers, but only in the necessary cases they can be used in small concentrations to treat yellowing, staining or stains. In spite of the numerous of current obtainable works aware of accelerating paper aging, an obvious association between artificial and natural aging is still missing. This point is a wonderful significance to scientists who dealing with paper conservation.

\section{References}

1. Librando, V., Minniti, Z., and Lorusso, S., Ancient and modern paper characterization by FT-IR and spectroscopy, Conservation Science in Cultural Heritage, 249-268. (2009).

2. Giorgi, R., Dei, L., Ceccato, M., Schettino, C. and Baglioni, P., Nanotechnologies for conservation of cultural heritage: paper and canvas deacidification, Langmuir, 18 (21), 8198-8203 (2002).

3. Daniels, V. D., The chemistry of paper conservation. Chemical Society Reviews. 25, 179-186 (1996).

4. Ardelean, E., \&Melniciue-Puica, N., Conservation of paper documents damaged by foxing, European Journal of Science and Theology, 9 (2), 117-124 (2013).

5. Choi, S., Foxing on paper: A literature review, Journal Of The American Institute For Conservation, 46 (2), 137-152 (2007).
6. Zervos, S., Alexopoulou, I., Paper conservation methods: A literature review, Cellulose, 22(5), 2859-2897 (2015).

7. Zheng, X, J., Foxing on $18^{\text {th }}$ Century Paper: A lithograph print, PrincetonUniversity, 1-20 (2006).

8. Clement,D., The Blistering of paper during Hydrogen peroxide bleaching, Journal of the American Institute for Conservation, 23 (1), 47-62 (1983).

9. Carr,D., Niven,B. and Campbell, L., Effects of selected aqueous treatments on the properties of two papers, Studies in Conservation, 51(3), 189. 198(2006).

10. Ouchi, A., Obata, T., Sakai, H. and Sakuragi, M., Laser bleaching of cellulosic fabrics by sodium borohydride aqueous solution; a total chlorine free process, Green Chem., 3, 221-223 (2001).

11. Duygu,Y. and Mehmet, K., Bleaching of wool with sodium borohydride, Journal of Engineered Fibers and Fabrics, 4(3), 45-50 (2009).

12.Erhardt, D. and Charless, S.T., Chemical degradation of cellulose in paper over 500 year, Restaurator, 26, 151-158 (2005)

13. Area, M.C. and Cheradame, H., Paper aging and degradation: Recent findings and research methods, Bio Reasources, 6 (4), 5307-5337 (2011).

14. David, J. H., Conservation treatment of the mi'kmaq prayer book, Journal de l'Association canadienne pour la conservation et la restauration (J.ACCR) 25, 21-29 (2000).

15. Ahmed. M. Youssef, Elsamahy, M. A., El-Sakhawy, M., Kamel S. Structural and electrical properties of paper-polyaniline composite. Carbohydrate Polymers 90, 1003- 1007 (2012).

16. Ahmed. M. Youssef, Kamel,S., El-Samahy. M.A. Morphological and antibacterial properties of modified paper by PS nanocomposites for packaging applications, Carbohydrate Polymers 98, 1166- 1172 (2013).

17. Ola, A. Mohamed; Ahmed. M. Youssef, Magda A. Elsamahy and Jean F. Bloch, Fire retardant cartoon by adding modified leather waste, Egypt. J. Chem, 59, 553-268 (2016) .

18. Ahmed. M. Youssef, Mohamed, S. A. , Abdel-Aziz, M. S. Abdel-Aziz,M. E. Turky, G. and Kamel, S. Biological studies and electrical conductivity of paper sheet based on PANI/PS/Ag-NPs nanocomposite, Carbohydrate Polymers 147, 333- 
343 (2016).

19. Williams, J.C., Chemistry of the Deacidification of paper, Bulletin of the American Group International Institute for Conservation of Historic and Artistic Works, 12 (1), 19 (1971).

20. Bansa, H., Accelerated ageing of paper, some ideas on its practical benefit, Restaurator, 23, 106 (2002).

21. Joel, N., Indictor, N., Hanlan, J.F. and Baer, N.S., The Measurement and Significance of $\mathrm{pH}$ in Paper Conservation, International Institute for Conservation of Historic and Artistic Works, 12 (2) , 119-125 (1972).

22. Strlic, M., Pihlar, B., Mauko, L., Kolar, J., Hocevar, S. and Ogorevc, B., A new electrode for microdetermination of paper ph, Restaurator, 26, 159171 (2005).

23. Junior, J.L.P., The development of micro-analytical methodologies for the characterization of the condition of paper, $9^{\text {th }}$ International Congress of IADA, Copenhagen, 15 (21), 107-114 (1999).

24. Nada, A.M.A., El-Sakhawy, M., Kamel, S. and Adel, A.M., Mechanical and electrical properties of paper sheets treated with chitosan and its derivatives, Carbohydrate Polymers, 63, 113-121 (2006).

25. Suryawanshi, D.G., Like paper, Birch Bark and its mechanical properties, Restaurator, 25, 75-80 (2004).

26. Abdel-Maksoud, G. and Marcinkowska, E., Changes in some properties of aged and historical parchment, Restaurator, 21, 138-157 (2000).
27. Abdel-Maksoud, G. and Al-saad, Z., Evaluation of cellulose acetate and chitosan used for the treatment of historical papers, Mediterranean Archaeology and Archaeometry, 9 (1), 69 - 87 (2009).

28. Burgess, H.D., Reyden, D.V.D. and Keyes, K., Bleaching: paper conservation catalog, Journal of the American Institute for Conservation, 1-38 (1989) .

29. Mohamed, S.I. and Rushdan, I., Effect of bleaching on coir fibre pulp and paper properties, J. Trop. Agric. And Fd. Sc, 42 (1), 51-61(2014).

30. Coates, J., Interpretation of infrared spectra, a practical approach, Encyclopedia of Analytical Chemistry, 10815-10837 (2000).

31. Leal-Ayala, D.R., Allwood, J.M., Schmidt, M. and Alexeev,I., Toner-print removal from paper by long and ultrashort pulsed lasers, Proceedings: Mathematical, Physical and Engineering Sciences, 468 (2144), 2272-2293 (2012).

32. Batterham, I. and Rai, R., A comparison of artificial ageing with 27 years of natural ageing, AICCM Book, Paper And Photographic Materials Symposium, 82-89 (2008).

33. Lojewska, J., Miskowiec, P., Lojewski, T. and Proniewicz, L.M., Cellulose oxidative and hydrolytic degradation: In situ FTIR approach, Polymer Degradation And Stability, 88, 512-520 (2005).

(Received 3/7/2017; accepted 20/8/2017) 


\section{تأثير مواد التبيض على الخواص الفيزيائية والمورفولوجية للصيانة العلاجية للورق}

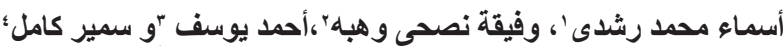

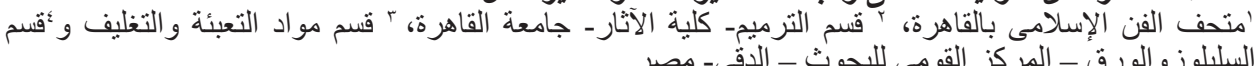

نظر الأن الورق الآثرى يعانى دائما من الإصفر ار و الدكانة وخاصتا بعد التقادم الطبيعى له، كما يمكن أن تظهر عليه

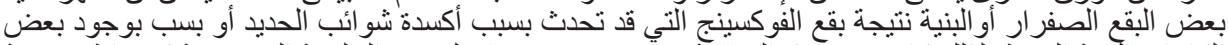

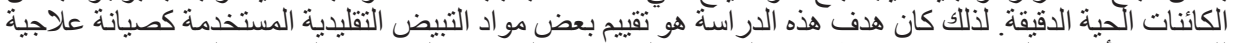

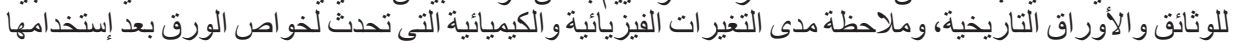

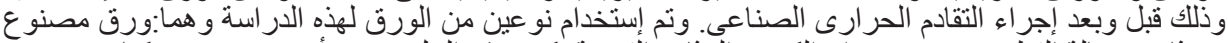

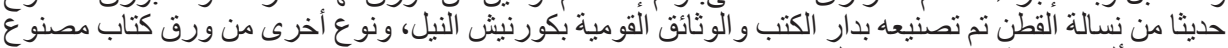

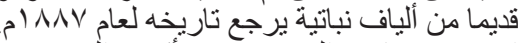

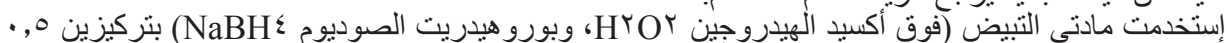

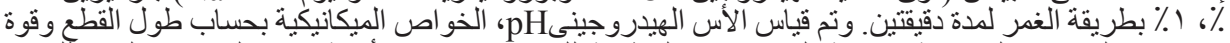

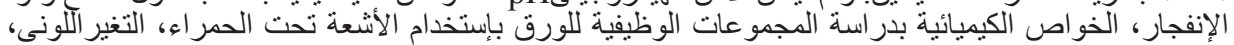

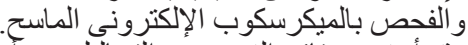

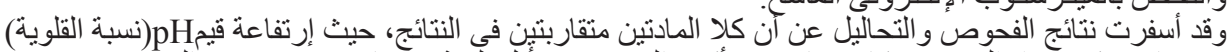

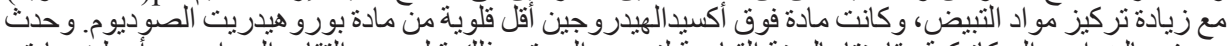

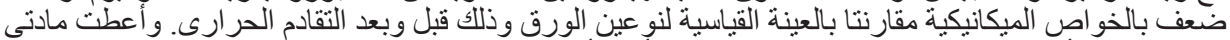

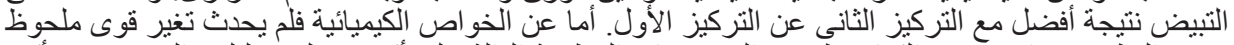

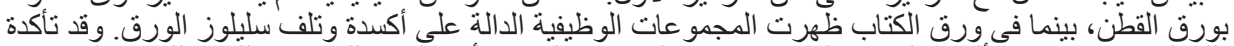

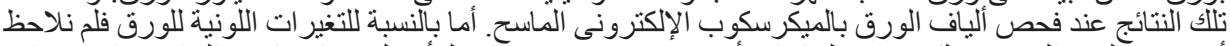

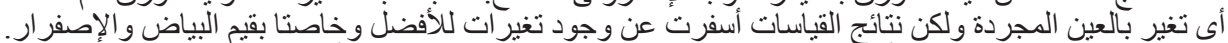

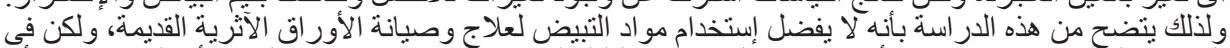

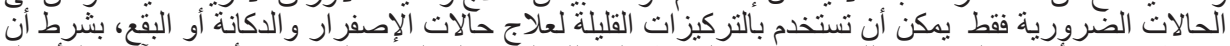

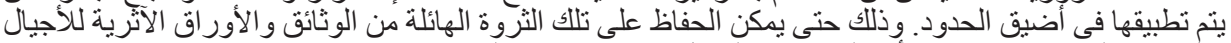
و الثعوب القادمة دون حدوث أى تلف نتيجة التنخل بمو اد قد تؤثر عليها فيما بعد. 